\title{
Introdução ao Estudo da Migração Internacional na Amazônia*
}

\section{Luis E. Aragón**}

\section{Introdução}

A migração internacional tornou-se um fenômeno de relevância mundial tanto para os países de destino como de origem ou de trânsito. A Organização Internacional para as Migrações (na sigla em inglês, International Organization for Migration (IOM) estima, para 2010, 214 milhões de migrantes internacionais, o que representaria $3,1 \%$ da população mundial (IOM, 2011). Há consenso entre os estudiosos de que o atual processo de globalização acelerou e alterou significativamente os padrões migratórios internacionais. A expansão do capitalismo, o empobrecimento de países europeus, as políticas favoráveis à imigração europeia e o fim da escravidão levaram a um aumento impressionante dos fluxos migratórios internacionais nas últimas décadas do século XIX e primeiras do século XX, período conhecido como a era das grandes migrações transoceânicas. Os fluxos dirigiam-se principalmente da Europa para o Novo Mundo, destacando-se como destinos principais Estados Unidos, Canadá, Argentina, Brasil e Austrália. Porém, esses fluxos tradicionais se transformaram profundamente nas últimas décadas. Segundo Martine (2005), em 1960, a maioria de migrantes internacionais residiam em países em desenvolvimento. Mas,

\footnotetext{
* Artigo recebido em 26 de janeiro de 2011 e aprovado para publicação em 25 de julho de 2011.

** Ph.D. em geografia pela Michigan State University, EUA, professor e pesquisador do Núcleo de Altos Estudos Amazônicos da Universidade Federal do Pará, coordenador da Cátedra UNESCO de Cooperação Sul-Sul para o Desenvolvimento Sustentável, pesquisador do CNPq e titular da Cátedra Milton Santos do Centro de Estudos Sociais da Universidade de Coimbra, Portugal. E-mail: aragon_naea@ufpa.br.
} 
em 2000, a proporção inverteu-se: $63 \%$ dos migrantes registrados residia nos países desenvolvidos, sendo que os maiores fluxos se dão de países em desenvolvimento para países desenvolvidos. Nesse contexto, a região de América Latina e Caribe converteu-se naquela de maior expulsão: um em cada dez migrantes internacionais nasceu em um país dessa região, sendo os Estados Unidos "a Meca dos migrantes" (MARTINE, 2005, p. 10).

O Brasil foi um dos destinos favoritos das grandes migrações de finais do século XIX e inícios do século XX, mantendo-se como um país receptor de migrantes até meados do século XX. Estima-se em mais de 5 milhões o número de imigrantes entre 1872 e 1972, vindos principalmente de Portugal, Itália, Japão, Alemanha e Espanha (LEVY, 1974). O censo brasileiro de 1900 registrou 1.074 .511 estrangeiros (6,16\% da população do país), aumentando, em 1920, para 1.565 .961 (5,11\% da população total), quando o país registrou o maior número de estrangeiros de sua história, conforme os censos. A partir daquele ano, a população estrangeira diminui constantemente até chegar a 651.226 pessoas no censo de 2000 (0,38\% da população), a mais baixa da história (PATARRA; BAENINGER, 2006). Entre 1950 e 1980, o Brasil foi considerado pelos especialistas como uma população fechada, ou seja, com crescimento populacional resultante quase que exclusivamente da relação entre nascimentos e mortes, dada a inexpressiva representação da migração internacional. Mas, a partir de 1980, o Brasil passou a enviar uma quantidade cada vez maior de pessoas a outros países, convertendo-se em um país não mais de recepção, mas de envio (CARVALHO; CAMPOS, 2006). Segundo Beltrão e Camarano (1998, p. 291), considerando apenas a migração internacional da população entre 15 e 39 anos:

[...] podemos dizer que a população brasileira perdeu nos anos oitenta aproximadamente 2 milhões de pessoas, das quais $53 \%$ eram homens [...]. A tendência de evasão internacional parece ter continuado nos anos 90. Considerando só o período 1991-96, a perda chegou a aproximadamente 1,1 milhão de pessoas. 
A reversão do fluxo migratório internacional no Brasil obedece a múltiplos fatores, incluindo, entre outros, a defasagem na transição demográfica do bloco de países desenvolvidos em relação ao de países em desenvolvimento, do processo de globalização e de redes sociais criadas ao longo da história da migração do país. Essa reversão vem acompanhada de novos padrões migratórios internacionais: aumento da proporção de imigrantes latino-americanos e norte-americanos, intensificação da migração entre blocos sub-regionais, como, por exemplo, entre os países do Mercosul, concentração nas metrópoles globais de São Paulo e Rio de Janeiro e a migração líquida, que se torna positivamente mais seletiva para o Brasil em termos educacionais e ocupacionais (PATARRA; BAENINGER, 2006; BAENINGER, 2001).

Contudo, apesar da importância que a migração internacional alcançou na mídia e na academia no mundo inteiro, existem somente uns poucos estudos esparsos sobre a migração internacional na Amazônia. Como se apresenta o processo de migração internacional na Amazônia e qual é sua importância nos destinos da região? Este artigo pretende aproximar-se dessa pergunta. Em primeiro lugar, o artigo destaca a dificuldade em se definir a Amazônia. Em seguida, apresenta algumas considerações sobre a migração internacional em nível da Grande Região, agregando o número de migrantes acumulados nas respectivas Amazônias nacionais, conforme os censos de população de cada país. E, finalmente, trata a problemática no caso da Amazônia brasileira, destacando os países de nascimento e a distribuição espacial dos migrantes na Amazônia Legal. O trabalho sintetiza os estudos realizados pelos investigadores do Grupo de Pesquisa Meio Ambiente, População e Desenvolvimento da Amazônia (MAPAZ), do Núcleo de Altos Estudos Amazônicos da Universidade Federal do Pará, e apresentados amplamente em Aragón (2009a).

\section{Amazônia}

Até onde vai a Amazônia e qual é a sua população eram as perguntas de um trabalho anterior (ARAGÓN, 2005a). Mas a dúvida persiste ainda hoje, pois não existe consenso quanto ao tamanho da região que se convencionou chamar de Amazônia, nem de sua população. Definir 
a área e calcular a população da Amazônia sempre foi um dos maiores desafios para pesquisadores e planejadores (OLIVEIRA JR., 2009). Além disso, para alguns, a Amazônia representa uma grande reserva de recursos naturais ou capital natural, despovoada, que necessita ser ocupada; para outros, a população já existente na região está gerando impactos ambientais negativos irreversíveis, sendo preciso, portanto, controlar ou mesmo frear seu crescimento populacional.

Gutiérrez et al. (2004, p. 21) sintetizam o desafio que representa definir a Amazônia:

As expressões Amazônia, Pan-Amazônia, Amazônia Sul-Americana, Região Amazônica ou Grande Amazônia compreendem diferentes enfoques, discernimentos e representações espaciais. Em geral, esses termos se referem à maior selva tropical úmida do planeta, localizada ao norte da América do Sul, à bacia hidrográfica do rio Amazonas, às nações que têm território nestas áreas, aos estados que promovem, através de ações conjuntas, o planejamento do desenvolvimento sustentável da Amazônia para preservar o meio ambiente e o uso racional dos recursos naturais, aos limites artificiais de conveniência político-administrativa para a aplicação de incentivos fiscais em territórios determinados, aos povos que a habitam, e a sua fauna terrestre e aquática. Esses conceitos apresentam a dificuldade de não poderem ser traduzidos facilmente em uma cartografia única, porque se referem a espaços diferentes, cujos limites não necessariamente coincidem. A Amazônia, como entidade unificada, só pode existir como uma amálgama de regiões. Dessa forma, pode-se afirmar que existem várias Amazônias que conformam uma grande região, onde cada uma tem uma distribuição regional diferente. ${ }^{1}$ 
No entanto, qual é a importância de se definir fisicamente a Amazônia? Para alguns, o que importa é o imaginário que tem convertido a Amazônia em uma espécie de marca capaz de agregar valor a tudo aquilo que leva seu nome, independentemente da área ou características físicas da região (AMARAL FILHO, 2008). Contudo, uma definição precisa da Amazônia é útil. Além de aspectos relacionados à soberania nacional, gestores de políticas públicas e investimentos na Amazônia necessitam saber com clareza onde localizar tais investimentos (ARAGÓN, 2007a). Manfred Grasserbauer (2005, p. vii), diretor do Instituto do Meio Ambiente e Sustentabilidade da Comissão Europeia (IMAS), argumenta, enfaticamente, em favor da necessidade de existir uma definição clara da região:

Definir a extensão geográfica da Amazônia é fundamental para numerosíssimos assuntos de ordem política, a começar por uma simples questão como a indicação da população local, e a terminar em problemas complexos como o cálculo do balanço do carbono na bacia do Amazonas como fator das alterações climáticas em nível planetário. Na verdade, a Amazônia é um conjunto de ecossistemas com impacto realmente mundial, pelo que o seu desenvolvimento sustentável assume a maior importância, não só para os países envolvidos, mas também para toda a comunidade internacional.

Estudos realizados pelo grupo MAPAZ, integrado por pesquisadores de todos os países amazônicos, utilizando informações dos censos de população de cada país, permitiram elaborar um mapa da Grande Amazônia com as divisões administrativas utilizadas nos censos ${ }^{2}$ (ARAGÓN, 2005b) (Mapa 1). Esse esforço representa um avanço no sentido de somar os diferentes critérios utilizados para definir a Amazônia, facilitando, inclusive, o cálculo de sua superfície e a realização de estudos populacionais em diferentes níveis de agregação. Somando as superfícies de todas as divisões administrativas, chega-se a uma estimativa da área 
total da Grande Amazônia de $7.430 .785 \mathrm{~km}^{2}$, o que representa mais de $53 \%$ da área total dos países amazônicos. Excetuando-se as Guianas, onde $100 \%$ do seu território foi considerado amazônico, nos demais países a Amazônia também representa uma parte considerável de seu território, especialmente nos dois maiores países, Brasil e Peru, onde a Amazônia representa cerca de $60 \%$ de seus respectivos territórios nacionais. Brasil, Peru e Colômbia, os três países amazônicos mais extensos, detêm mais de $84 \%$ da área total da região (Tabela 1 ).

Calcular o tamanho da população dessa imensa região é outro grande desafio. Na verdade, não existe um cálculo exato da população da Grande Amazônia; existem somente estimativas pouco exatas que devem ser tomadas com cautela e que variam entre 20 e 37 milhões de pessoas (CDEA, 1992; YARZÁBAL et al., 1992; FFLA, 2002; PNUMA/OTCA, 2006).

\section{Mapa 1}

A Grande Amazônia

\section{A Grande Amazônia}

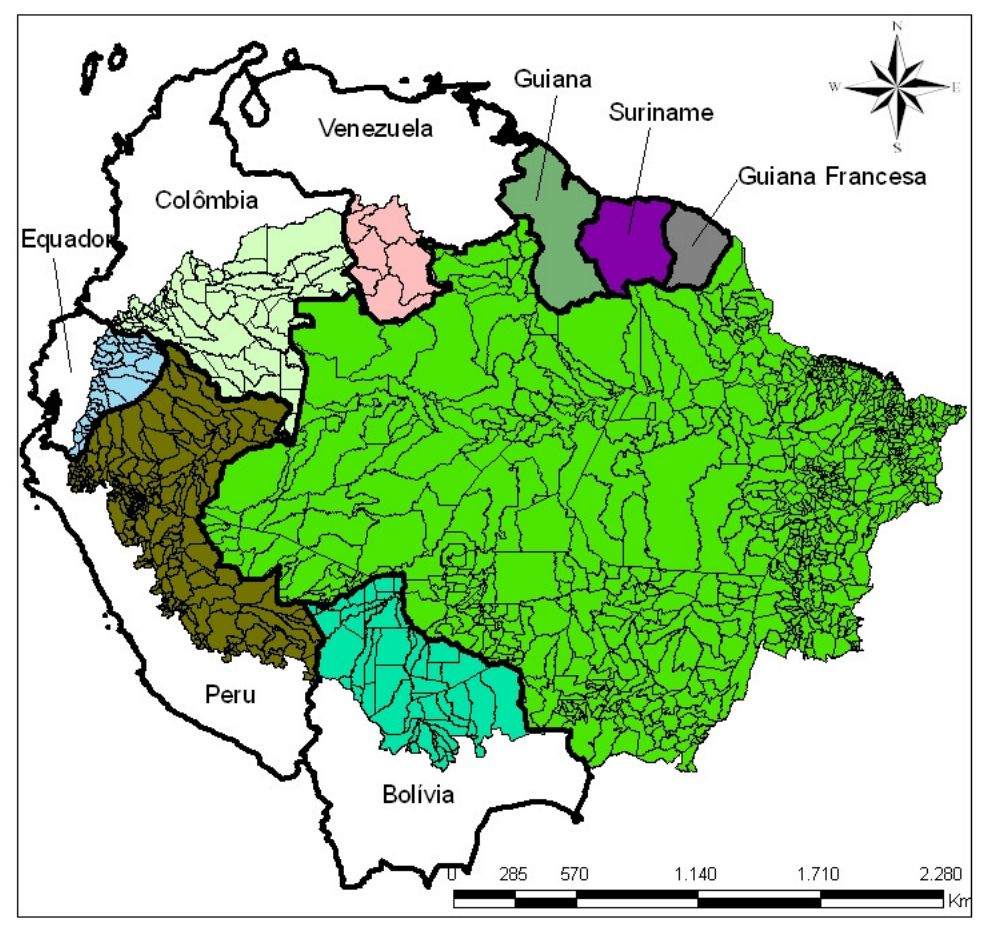

Mapa de Localização

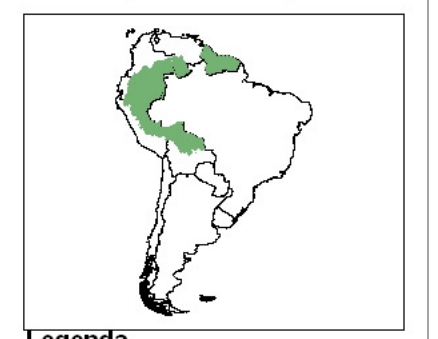

Legenda

$\square$ Países Amazônicos

Guiana Francesa

Suriname

Guiana

Amazônia Venezuelana (municípios)

Amazônia Colombiana (municípios)

Amazônia Equatoriana (cantones)

Amazônia Peruana (distritos)

Amazônia Boliviana (municípios)

Amazônia Brasileira (municípios)

Fonte: Adaptado de Aragón, 2005 Data: $25 / 11 / 2009$ Lir

Contato: rodrrigao@hotmail.com

Fonte: Aragón (2005a, p. 16), adaptado por Lira (2010). 
Introdução ao Estudo da Migração Internacional na

Amazônia

\section{Tabela 1}

Área e População Total da Grande Amazônia, por País

\begin{tabular}{|c|c|c|c|c|c|c|c|c|c|}
\hline \multicolumn{4}{|c|}{ Pais } & \multicolumn{6}{|c|}{ Amazônia } \\
\hline \multirow[b]{2}{*}{ Nome } & \multirow[b]{2}{*}{$\begin{array}{l}\text { Ano } \\
\text { Censo }\end{array}$} & \multirow[b]{2}{*}{ Área } & \multirow[b]{2}{*}{ População } & \multicolumn{3}{|c|}{ Área } & \multicolumn{3}{|c|}{ População } \\
\hline & & & & Total & $\begin{array}{l}\% \\
\text { País }\end{array}$ & $\begin{array}{c}\% \\
\text { Região }\end{array}$ & Total & $\begin{array}{c}\% \\
\text { País }\end{array}$ & $\begin{array}{c}\% \\
\text { Região }\end{array}$ \\
\hline Bolívia & 2001 & 1.098 .581 & 8.274 .325 & 398.000 & 36,23 & 5,31 & 805.101 & 9,73 & 2,75 \\
\hline Peru & 2007 & 1.285 .215 & 27.412 .157 & 759.057 & 59,06 & 10,13 & 4.574 .375 & 16,69 & $|5,6|$ \\
\hline Equador & 2001 & 256.730 & 12.156 .608 & II5.745 & 45,08 & 1,54 & 548.419 & 4,51 & I,87 \\
\hline Colômbia & 2005 & I.I38.906 & 41.468 .384 & 477.772 & 41,95 & 6,37 & 747.267 & 1,80 & 2,55 \\
\hline Venezuela & 2001 & 916.445 & 24.915 .902 & 183.500 & 20,02 & 2,45 & 113.722 & 0,46 & 0,39 \\
\hline Guiana & 2002 & 214.999 & 751.223 & 214.999 & 100,00 & 2,87 & 751.223 & 100,00 & 2,56 \\
\hline Suriname & 2004 & 163.470 & 492.829 & 163.470 & 100,00 & 2,18 & 492.829 & 100,00 & 1,68 \\
\hline Guiana Fr. & 2006 & 84.000 & 205.956 & 84.000 & 100,00 & $I, I 2$ & 205.956 & 100,00 & 0,70 \\
\hline Brasil & 2000 & 8.514 .876 & 169.872 .856 & 5.098 .934 & 59,88 & 68,03 & 21.073 .967 & $|2,4|$ & 71,89 \\
\hline Total & & 1.367.3222 & 285.550 .240 & 7.495.477 & 54,82 & 100,00 & 29.312 .859 & 10,26 & 100,00 \\
\hline
\end{tabular}

Fonte: Censos nacionais. Atualizado de Aragón (2005a).

$\mathrm{Na}$ falta de uma estimativa mais rigorosa, poderíamos totalizar a população somando as populações das Amazônias nacionais, apesar da baixa cobertura e da limitação de os censos serem realizados em anos diferentes. ${ }^{3} \mathrm{O}$ resultado seria, então, uma estimativa conservadora da população total da Grande Amazônia, ultrapassando os 29 milhões de pessoas, o que representa aproximadamente $10 \%$ da população total dos países amazônicos (Tabela 1). Em nível nacional, a Amazônia contribui relativamente pouco para o total da população dos países, variando de $16,69 \%$ no Peru a $0,46 \%$ na Venezuela (excetuando o caso das Guianas, onde $100 \%$ da população é considerada amazônica). No Brasil, a população da Amazônia Legal contribui com aproximadamente $12 \%$ da população nacional. ${ }^{4}$ Internamente, a população da Grande Amazônia está concentrada em dois países: Brasil $(71,89 \%)$ e Peru $(15,61 \%)$. A população das três Guianas juntas não representa sequer $5 \%$ da população total da região.

As proporções de área e população conforme os territórios amazônicos permitem perceber as desigualdades das Amazônias nacionais, deduzindo-se dessa situação a complexidade dos fenômenos regionais. Por exemplo, a população das três Guianas juntas chega escassamente 
à população da Região Metropolitana de Belém e, em termos de área, esses territórios podem caber dentro de alguns municípios da Amazônia brasileira. O território de toda Colômbia é um pouco menor do que o território do estado do Pará, portanto, sua Amazônia, que representa pouco mais de $41 \%$ do território do país, cabe em menos da metade do Estado do Pará. Essas comparações permitem pensar que as problemáticas regionais e também as políticas variam de país para país. Formular políticas para a Amazônia equatoriana $\left(115.745 \mathrm{~km}^{2}\right.$ e 548.515 pessoas), por exemplo, é diferente de formular para a Amazônia brasileira (5.098.934 km² e 21.073.967 pessoas). Com respeito à relação entre meio ambiente e população na região, estudos do Grupo MAPAZ demonstram que as prioridades de pesquisa e políticas públicas na Amazônia variam consideravelmente entre os países. Por exemplo, enquanto o Brasil centra suas prioridades no controle do desmatamento, o Equador preocupa-se em garantir a exploração de petróleo na região, cuja produção representa cerca de $40 \%$ das exportações do país, e a Colômbia foca sua atenção em dominar as Forças Armadas Revolucionárias da Colômbia (FARC) e controlar o narcotráfico (ARAGÓN, 2007b).

\section{Migração internacional}

Os países amazônicos contam hoje com censos realizados na década de 2000 e permitem sistematizar alguns dados para traçar uma radiografia da migração internacional na Grande Amazônia, apesar das limitações dos mesmos. Na realidade, os dados dos censos, especialmente na Amazônia, oferecem somente "indícios", "pistas", "insights", para pesquisas mais aprofundadas, mas que são extremamente relevantes para o descobrimento de elementos específicos que expliquem o fenômeno (ARAGÓN, 2009a).

As limitações dos censos determinaram uma subutilização nos estudos de migração internacional na Amazônia, tanto no Brasil como nos demais países. Nesse sentido, os estudos do Grupo MAPAZ representam uma contribuição para expor tanto as limitações como a utilidade dessa fonte. Os resultados na base dos censos disponíveis permitirão 


\section{Introdução ao Estudo da Migração Internacional na \\ Amazônia}

analisar comparações com a próxima rodada de censos e apontar melhoria dos mesmos.

\section{Migração internacional na Grande Amazônia}

Uma primeira aproximação revela que, no mínimo, residiriam por volta do ano 2000 na Grande Amazônia 175.616 pessoas nascidas no exterior, o que representaria $8,07 \%$ da população estrangeira dos países amazônicos em seu conjunto (Tabela 2). O país amazônico com a maior população de estrangeiros é a Venezuela, com quase o dobro de estrangeiros do Brasil. No Brasil, país mais populoso, a população estrangeira da Amazônia representa 4,57\% do total de estrangeiros do país, e 16,94\% da população estrangeira da Grande Amazônia. As Guianas e o Brasil juntos acolhem mais de $85 \%$ de todos os estrangeiros que habitam a região.

\section{Tabela 2}

População Estrangeira dos Países Amazônicos e na Amazônia no Ano do Censo

\begin{tabular}{|c|c|c|c|c|c|c|}
\hline \multirow[t]{2}{*}{ Pais } & \multirow{2}{*}{$\begin{array}{l}\text { Ano do } \\
\text { Censo }\end{array}$} & \multicolumn{2}{|c|}{ População estrangeira do pais } & \multicolumn{3}{|c|}{ População estrangeira da Amazônia } \\
\hline & & Absoluta & $\begin{array}{c}\% \text { da } \\
\text { população do } \\
\text { pais }\end{array}$ & Absoluta & $\begin{array}{l}\text { \% da popula- } \\
\text { ção estrangeira } \\
\text { do pais }\end{array}$ & $\begin{array}{c}\text { \% da popula- } \\
\text { ção estrangeira } \\
\text { da região }\end{array}$ \\
\hline Bolívia & 2001 & 94.391 & $\mathrm{I}, 14$ & 6.879 & 7,29 & 3,91 \\
\hline Peru & 2007 & 81.636 & 0,30 & 7.319 & 8,96 & 4,17 \\
\hline Equador & 2001 & 104.130 & 0,86 & 7.036 & 6,76 & 4,00 \\
\hline Colômbia & 2005 & 109.971 & 0,26 & 2.673 & 2,43 & 1,52 \\
\hline Venezuela & 2001 & 1.014 .938 & 4,07 & 2.244 & 0,22 & 1,28 \\
\hline Guiana & 2002 & 9.451 & 1,26 & 9.451 & 100,00 & 5,38 \\
\hline Suriname & 2004 & 32.569 & 6,61 & 32.569 & 100,00 & 18,55 \\
\hline Guiana & 2006 & 77.704 & 37,72 & 77.704 & 100,00 & 44,25 \\
\hline Francesa & & & & & & \\
\hline Brasil & 2000 & 651.226 & 0,38 & $29.74 \mid$ & 4,57 & 16,94 \\
\hline Total & & 2.176 .016 & 0,76 & 175.616 & 8,07 & 100,00 \\
\hline
\end{tabular}

Fonte: Censo de cada país. Atualizado de Aragón (2009b).

Onde nasceram esses migrantes? Segundo os estudos realizados pelos pesquisadores do grupo MAPAZ, cerca de $50 \%$ do total de estrangeiros que residiam na Amazônia no momento do censo nasceram nos próprios países amazônicos (ARAGÓN, 2009a). Esses estudos permi- 
tem deduzir que, em geral, existe uma forte influência mútua entre os países amazônicos, especialmente entre os fronteiriços. A Amazônia brasileira acolhe principalmente bolivianos (15,31\%) e peruanos (13,65\%) (DO CARMO; JAKOB, 2009); e a Amazônia boliviana concentra principalmente brasileiros $(64,43 \%)$ e peruanos $(6,68 \%)$ (VARGAS BONILLA, 2009), enquanto a Amazônia peruana recebe principalmente brasileiros $(21,87 \%)$, colombianos $(20,26)$ e alguns europeus e norte-americanos (LIMACHI HUALLPA, 2009). O Equador não faz fronteira com o Brasil e acolhe poucos migrantes desse país e a recíproca é também verdadeira; enquanto concentra na sua Amazônia uma enorme proporção de colombianos (75,75\%), localizados principalmente na província de Sucumbios, que faz fronteira com a Colômbia, (LEÓN et. al., 2009), no lado colombiano, há também certo número de equatorianos, mas em proporção muito menor (6,29\%), localizados sobretudo no departamento de Putumayo, que se limita com a província equatoriana de Sucumbios. A Amazônia colombiana recebe majoritariamente peruanos $(21,85 \%)$ e brasileiros $(12,04 \%)$, localizados principalmente na tríplice fronteira de Letícia/Tabatinga (SANDINO, 2009). A Amazônia colombiana recebe poucos venezuelanos $(1,23 \%)$, mas os imigrantes na Amazônia venezuelana são na sua maioria colombianos $(68,45 \%)$ e brasileiros (6,15\%) (ARAGÓN, 2009b). Certamente, o padrão migratório da Amazônia colombiana está fortemente influenciado pelo conflito armado que vive o país, empurrando muitos desplazados ${ }^{5}$ para os países fronteiriços de sua Amazônia. Finalmente, as Guianas recebem grande impacto do Brasil, mas a Amazônia brasileira acolhe poucos migrantes vindos das Guianas. Na Guiana, 27,82\% dos migrantes são brasileiros (CORBIN, 2009), e proporções significativas apresentam-se também no Suriname $(17,88 \%)$ (JUBITHANA-FERNAND, 2009) e na Guiana Francesa (15,40\%) (BARRET, 2005; ARAGÓN, 2009b), mas a presença de migrantes desses três territórios na Amazônia brasileira é somente de 5\% nascidos na Guiana, de 0,38\% nascidos no Suriname e de 2,79\% nascidos na Guiana Francesa (DO CARMO;JAKOB, 2009). A presença de brasileiros nas Guianas somente rivaliza com aqueles vindos das próprias Guianas e do Caribe, e, no caso do Suriname, da Holanda, pelos laços culturais existentes. A re- 
lação entre a Amazônia brasileira e as Guianas se dá principalmente nas áreas de garimpo (AROUCK, 2001; CORBIN, 2007; PINTO, 2009). Só no Suriname, estima-se 20 mil imigrantes brasileiros, a maioria ilegal (JUBITHANA-FERNAND, 2009).

De certa forma, a imigração de brasileiros na Guiana e no Suriname compensa a alta emigração desses países. Corbin (2009) na Guiana e Jubithana-Fernand (2009) no Suriname documentam elevada emigração, especialmente para os Estados Unidos, a Europa e o Caribe, composta principalmente de profissionais. Segundo Corbin (2009), a emigração da população qualificada da Guiana é considerada uma das mais elevadas do mundo. Em 1990, 70\% dos indivíduos com mais de treze anos de escolaridade saíram do país só para os Estados Unidos, e, durante 1965-2000, cerca de 43\% dos trabalhadores do país com ensino secundário e $89 \%$ com educação superior migraram para países-membros da Organização para a Cooperação e Desenvolvimento Econômico (OCDE).

No caso de Suriname, entre 1972 e 2005, o saldo migratório foi negativo e somente a partir de 1994 a emigração apresentou sinais de declínio. No entanto, o saldo migratório tornou-se positivo a partir de 2006 devido, em grande parte, à imigração de brasileiros atraídos pela febre do ouro (JUBITHANA-FERNAND, 2009). Segundo JubithanaFernand (2009), entre os emigrantes do Suriname predominam as mulheres, em razão principalmente do elevado número de famílias no país chefiadas por elas e da fuga de profissionais como enfermeiras e professoras.

Esses estudos também revelam traços da história migratória da Amazônia. Por exemplo, na Guiana, há imigrantes que nasceram na Índia e na China; no Suriname, há aqueles nascidos na Holanda; e, na Amazônia brasileira, aparecem imigrantes do Japão, Itália, Espanha e Portugal. Eles revelam também certa presença de norte-americanos e europeus principalmente nas Amazônias do Peru e do Equador, resultado 
da exploração de petróleo nessas duas regiões (LIMACHI HUALLPA, 2009; LEÓN, et.al., 2009).

Em resumo, os estudos realizados pelos pesquisadores do Grupo MAPAZ permitem concluir em nível da Grande Amazônia que:

1. há uma intensa mobilidade entre as três Guianas, com influência do Caribe, e do Brasil e da Holanda, no caso do Suriname. Os documentos elaborados deixam claro também que Guiana e Suriname sofrem enormemente da fuga de profissionais, principalmente para os Estados Unidos e a Europa (BYNOE; BRISTOL, 2009; CORBIN, 2009; JUBITHANA-FERNAND, 2009);

2. a Amazônia dos países andinos experimenta frequente mobilidade bilateral, ou recíproca, excetuando Venezuela e Colômbia, pois a Colômbia apresenta alta participação de colombianos na Amazônia venezuelana, mas não o inverso;

3. o Brasil exerce influência sobre os demais países amazônicos, inclusive nas Guianas, onde se concentra grande número de brasileiros vinculados à exploração de ouro;

4. grande parte dos migrantes da Amazônia brasileira procede dos países amazônicos fronteiriços e apresenta padrões de localização característicos de cada país, como se verá na próxima seção.

\section{Migração internacional na Amazônia brasilleira}

De acordo com o censo de 2000, a Amazônia Legal brasileira alberga 29.741 residentes nascidos no exterior, principalmente na Bolívia, Peru, Japão, Portugal e Paraguai (Tabela 3). Esses países de nascimento revelam correntes migratórias antigas como as dos japoneses, portugueses e italianos. Tal padrão sofre modificações quando se considera o país de residência daqueles que moravam fora do Brasil em 1995, no total 4.443 pessoas. Desaparecem das primeiras colocações Japão (do $3^{\circ}$ para o $14^{\circ}$ lugar), Portugal (do $4^{\circ}$ para sem registro) e Itália (de $8^{\circ}$ para $18^{\circ}$ lugar) e emergem em seus lugares países amazônicos e outros países das Américas. Essa mudança acompanha a tendência de aumen- 


\section{Introdução ao Estudo da Migração Internacional na Amazônia}

to da chegada ao Brasil de migrantes provenientes de países vizinhos (PATARRA; BAENINGER, 2006; BAENINGER, 2001).

\section{Tabela 3}

País de Nascimento e de Residência em 1995 dos Migrantes Internacionais Residentes na Amazônia Legal em 2000, por Ordem do Volume de Pessoas

\begin{tabular}{|c|c|c|c|c|}
\hline \multirow{2}{*}{ Pais } & \multicolumn{2}{|c|}{ Nascimento } & \multicolumn{2}{|c|}{ Residência em 1995} \\
\hline & Ordem & Volume & Ordem & Volume \\
\hline Bolívia & 01 & 4.554 & 02 & 686 \\
\hline Peru & 02 & 4.059 & 01 & 805 \\
\hline Japão & 03 & 3.039 & 14 & 93 \\
\hline Portugal & 04 & 2.979 & & \\
\hline Paraguai & 05 & 2.941 & 04 & 347 \\
\hline Guiana & 06 & 1.486 & 06 & 334 \\
\hline Colômbia & 07 & 1.375 & 03 & 401 \\
\hline Itália & 08 & 1.240 & 18 & 63 \\
\hline Estados Unidos & 09 & 973 & 07 & 240 \\
\hline Venezuela & 10 & 837 & 05 & 339 \\
\hline Guiana Francesa & II & 587 & 09 & $|5|$ \\
\hline Argentina & 12 & 556 & & \\
\hline Alemanha & 13 & 525 & 12 & 103 \\
\hline Outros paises da Ásia & 14 & 454 & 17 & 67 \\
\hline País estrangeiro sem especificação & 15 & 399 & 13 & 94 \\
\hline Libano & 16 & 376 & & \\
\hline França & 17 & 373 & 16 & 82 \\
\hline Chile & 18 & 316 & 15 & 84 \\
\hline Outros paises da América & 19 & 282 & 08 & 178 \\
\hline Espanha & 20 & 282 & & \\
\hline Outros paises da Europa & 21 & 265 & II & $|4|$ \\
\hline Holanda & 22 & 210 & & \\
\hline Uruguai & 23 & 208 & & \\
\hline Outros países da África & 24 & 198 & & \\
\hline Angola & 25 & 185 & 21 & 3 \\
\hline Cuba & 26 & 178 & 10 & 146 \\
\hline İndia & 27 & $|3|$ & 19 & 62 \\
\hline Coreia do Norte e Coreia do Sul & 28 & 118 & & \\
\hline Grã-Bretanha & 29 & 117 & & \\
\hline Suriname & 30 & 114 & & \\
\hline Bélgica & 31 & 108 & & \\
\hline Suiça & 32 & $10 \mid$ & & \\
\hline Equador & 32 & 100 & & \\
\hline Austrália/0ceania & 33 & 23 & 20 & 25 \\
\hline Total & & 29.741 & & 4.443 \\
\hline
\end{tabular}

Fonte: Adaptado de Do Carmo e Jakob (2009, p. 208-210). 
Dos 29.741 estrangeiros residentes na Amazônia Legal brasileira no momento do censo, 13.113 (44\%) nasceram em países amazônicos, especialmente na Bolívia (34,72\%) e no Peru (30,95\%), e estão concentrados majoritariamente no Amazonas (34,34\%) e em Rondônia $(20,64 \%)$ (Tabela 4).

A distribuição espacial desses migrantes varia conforme o país de nascimento. Os migrantes nascidos no Peru agrupam-se principalmente nos municípios ao longo da fronteira com esse país, nos maiores centros urbanos da região e ao longo da calha do rio Amazonas (Mapa 2); os bolivianos ocupam quase que exclusivamente municípios fronteiriços do Acre, Rondônia e Mato Grosso (Mapa 3); e os colombianos se situam em Tabatinga, cidade gêmea de Letícia, em Manaus, e na Cabeça do Cachorro (Mapa 4). Os migrantes nascidos na Venezuela e Guiana situam-se principalmente em Roraima (Mapas 5 e 6) e os do Suriname e Guiana Francesa em Amapá e Pará (Mapas 7 e 8). A migração de equatorianos, cujo país não possui fronteira com o Brasil, apresenta o menor número em relação aos demais países amazônicos (cem pessoas) e encontra-se espalhada em uns poucos pontos da Amazônia brasileira, com maior concentração em Manaus (Mapa 9).

\section{Tabela 4}

Número de Migrantes Internacionais Residentes na Amazônia Legal Nascidos nos Países Amazônicos, por Unidades da Federação, 2000

\begin{tabular}{lrrrrrrrrr}
\hline $\begin{array}{c}\text { Unidades da } \\
\text { Federação de } \\
\text { residência }\end{array}$ & Bolívia & Colômbia & Equador & Guiana & $\begin{array}{c}\text { Guiana } \\
\text { Ronazônicos de nascimento }\end{array}$ & Peru & Suriname & Venezuela & Total \\
Rondônia & 2.353 & 54 & 9 & - & - & 262 & - & 28 & 2.707 \\
Acre & 1.010 & 24 & - & - & - & 510 & - & - & 1.544 \\
Amazonas & 113 & 1.063 & 42 & 97 & 74 & 2.874 & - & 253 & 4.516 \\
Roraima & 10 & 62 & - & 1.312 & 12 & 118 & - & 463 & 1.977 \\
Pará & 127 & 95 & - & 63 & 84 & 190 & 110 & 47 & 716 \\
Amapá & - & 10 & - & - & 410 & 45 & - & - & 464 \\
Tocantins & 42 & 12 & 17 & - & - & 11 & 4 & 4 & 91 \\
Maranhão & 10 & - & 10 & - & 8 & 7 & - & 37 & 73 \\
Mato Grosso & 888 & 56 & 21 & 14 & - & 42 & - & 4 & 1.025 \\
total & 4.554 & 1.375 & 100 & 1.486 & 587 & 4.059 & 114 & 837 & 13.113 \\
\hline
\end{tabular}

Fonte: IBGE, Amostra Censo Demográfico de 2000. Tabulações Especiais MAPAZ/UFPA. Elaborado por Lira (2010). 
Essas evidências revelam que a migração internacional na Amazônia brasileira passa por mudanças importantes no que se refere a seus padrões de origem e distribuição espacial. As melhorias dos transportes e condições de comunicação, os acordos bilaterais, os planos de cooperação internacional, como os da Organização do Tratado de Cooperação Amazônica, e de integração física, como a Iniciativa de Integração da Infraestrutura Regional Sul-Americana (IIRSA), poderão acelerar este processo com desdobramentos significativos para o desenvolvimento da Amazônia brasileira e dos demais países (ARAGÓN; OLIVEIRA JR., 2009).

\section{Conclusões}

Nos cinco séculos de história desde a chegada de Colombo, argumenta Pellegrino (2003, p. 11), a região da América Latina e do Caribe passou por quatro grandes etapas migratórias. A primeira, da conquista à independência, caracterizou-se pela ocupação do território pela população que vinha dos países colonizadores e pela população escrava africana. A segunda correspondeu à época das grandes migrações europeias para o novo mundo durante a segunda metade do século XIX e princípios do século $\mathrm{XX}$, quando a região recebeu grande quantidade de pessoas desse continente. A terceira, de 1930 a 1960, apresentou retração dos fluxos internacionais tradicionais e o aumento das migrações internas para as grandes cidades, e a migração internacional adquiriu um caráter regional e fronteiriço. A quarta fase, ou contemporânea, se inicia nas últimas décadas do século $\mathrm{XX}$, com o aumento constante da emigração tornando negativos os saldos migratórios de muitos países.

A pergunta que surge é: e a próxima etapa? O Instituto das Migrações Internacionais da Universidade de Oxford tenta uma previsão (IMI, 2006, p. 13):

O declínio mundial das taxas de natalidade poderá vir a colocar em questão a hipótese de existência de um viveiro inesgotável de migrantes laborais, prontos a deslocar-se para os países in- 
dustrializados, com vista a prover as necessidades econômicas. À medida que os países forem avançando na transição demográfica, as suas taxas de dependência aumentarão nos próximos decênios. A médio e longo prazos, uma concorrência acrescida no acesso a mão de obra poderá transformar radicalmente as migrações mundiais e as respostas políticas de maneira dificilmente imaginável. Por exemplo, a fraca taxa de natalidade da China, novo gigante industrializado, poderia criar um déficit de mão de obra importante, e, a mais longo prazo, déficits similares poderiam emergir em outras regiões clássicas de emigração, como o Norte da África e a América Latina, onde as taxas de natalidade tiveram um rápido decréscimo.

Na Amazônia, o processo de migração internacional parece seguir a história da América Latina analisada por Pellegrino (2003) e se tornará mais dinâmico e complexo em função do andamento de políticas de desenvolvimento na busca da integração regional e econômica e da expansão dos efeitos da globalização. Ao final, argumenta Martine (2005, p. 3), a globalização "dispensa fronteiras, muda parâmetros diariamente, ostenta luxos, esbanja informações, estimula consumos, gera sonhos e, finalmente, cria expectativas de vida melhor”. Daí a explosão migratória do Sul para o Norte.

Em consequência, aceitar a migração internacional como um fenômeno necessário e inevitável do processo de globalização requer uma melhor gestão e não somente medidas de controle (HILY, 2003). Considerando a dimensão que tomou a emigração internacional, alguns países amazônicos têm desenvolvido programas especiais para estudar esse fenômeno em busca de uma melhor gestão ao invés de enfatizar somente o controle. É o caso dos trabalhos que vêm sendo realizados no Peru (INEI, 2007; 2008) e no Equador (LEÓN, et. al., 2009). 


\section{Introdução ao Estudo da Migração Internacional na}

Amazônia

A síndrome do brain drain, que tanto assola a Guiana e o Suriname, é outro assunto que merece atenção especial na Amazônia à luz de novos debates e propostas. Para alguns, a questão deveria mudar de foco de análise, de "drenagem de cérebros" para "circulação de cérebros" (PELLEGRINO, 2003, p. 26) e tomar vantagem de redes de diáspora, de intercâmbios acadêmicos, de "remessas de conhecimento" e de outras formas de fortalecimento das capacidades em países em desenvolvimento, que o próprio processo de migração internacional tende a fortalecer. Organismos como a Organização do Tratado de Cooperação Amazônica (OTCA), a Associação de Universidades Amazônicas (UNAMAZ) e a cúpula de chefes de Estado e de governo da América do Sul deverão ter papel protagonista neste assunto.

A participação da mulher em fluxos de migrações internacionais é cada vez mais reconhecida (MARTINE, 2005), o que tem levado a redefinir relações de gênero e o empoderamento das mulheres migrantes e "ficantes". Na Amazônia, essas relações são evidentes, por exemplo, no estudo de Rodrigues (2009). É um tema que merece mais aprofundamentos.

Finalmente, a migração internacional contemporânea vem acompanhada de processos ilícitos que precisam ser mais bem conhecidos e tratados. A Amazônia não pode ficar ausente desses debates. 


\section{Luis E. Aragón}

\section{Mapa 2}

Municípios de Residência, na Amazônia Brasileira, de Migrantes Nascidos no Peru, 2000

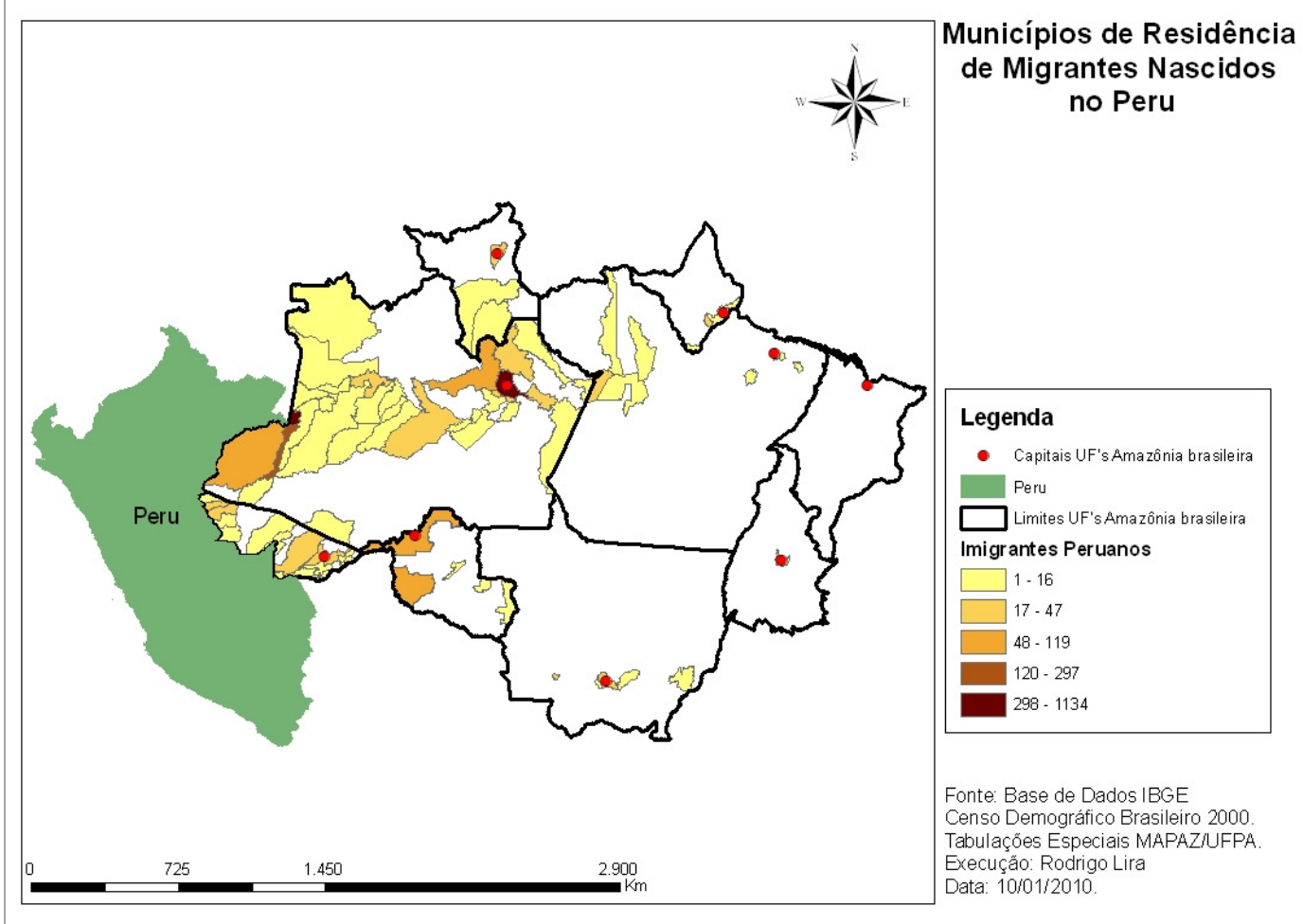

Fonte: IBGE, 2000. Elaborado por Lira (2010). 
Introdução ao Estudo da Migração Internacional na Amazônia

\section{Mapa 3}

Municípios de Residência, na Amazônia Brasileira, de Migrantes Nascidos na Bolívia

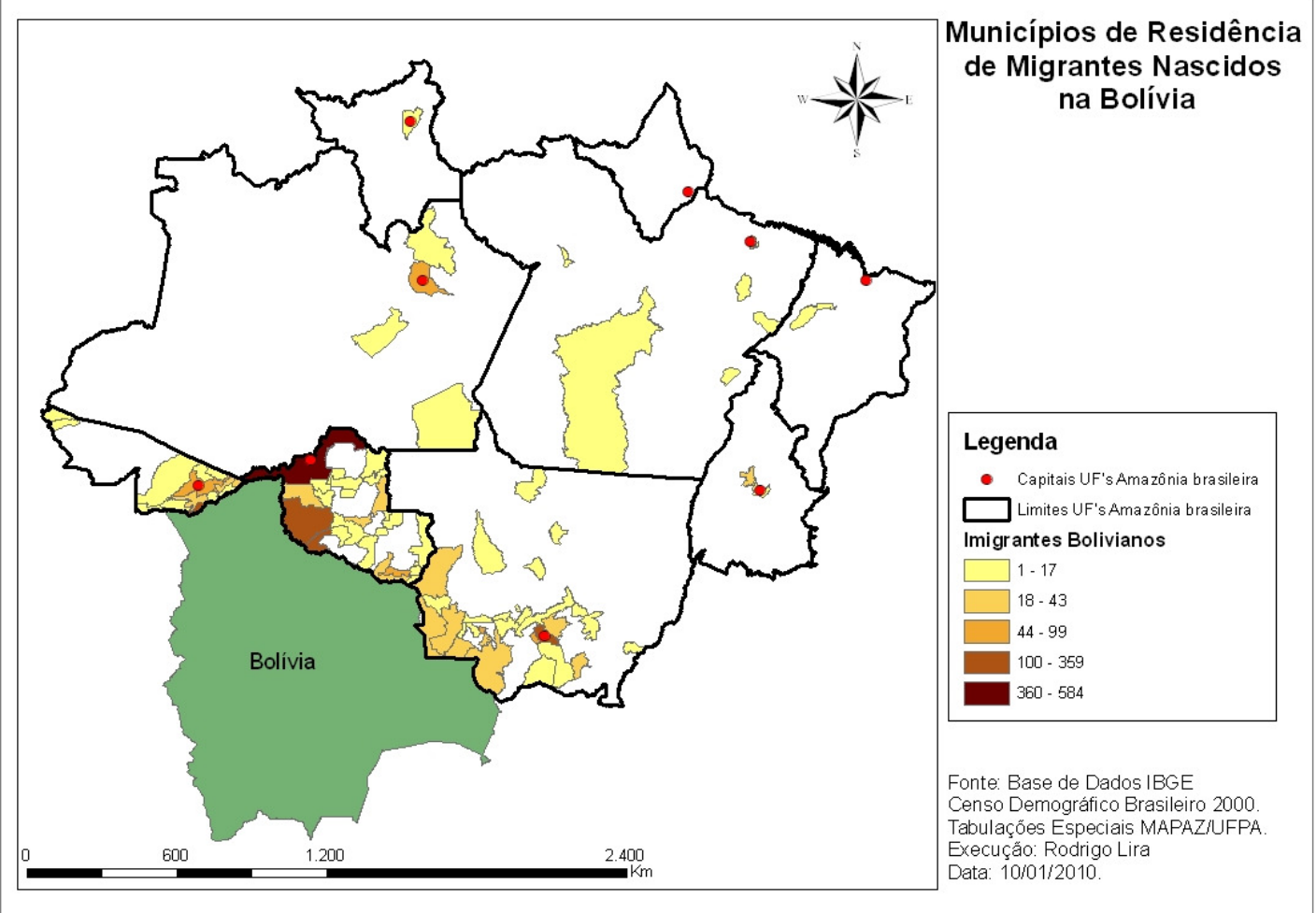

Fonte: IBGE, 2000. Elaborado por Lira (2010). 


\section{Luis E. Aragón}

\section{Mapa 4}

Municípios de Residência, na Amazônia Brasileira, de Migrantes Nascidos na Colômbia

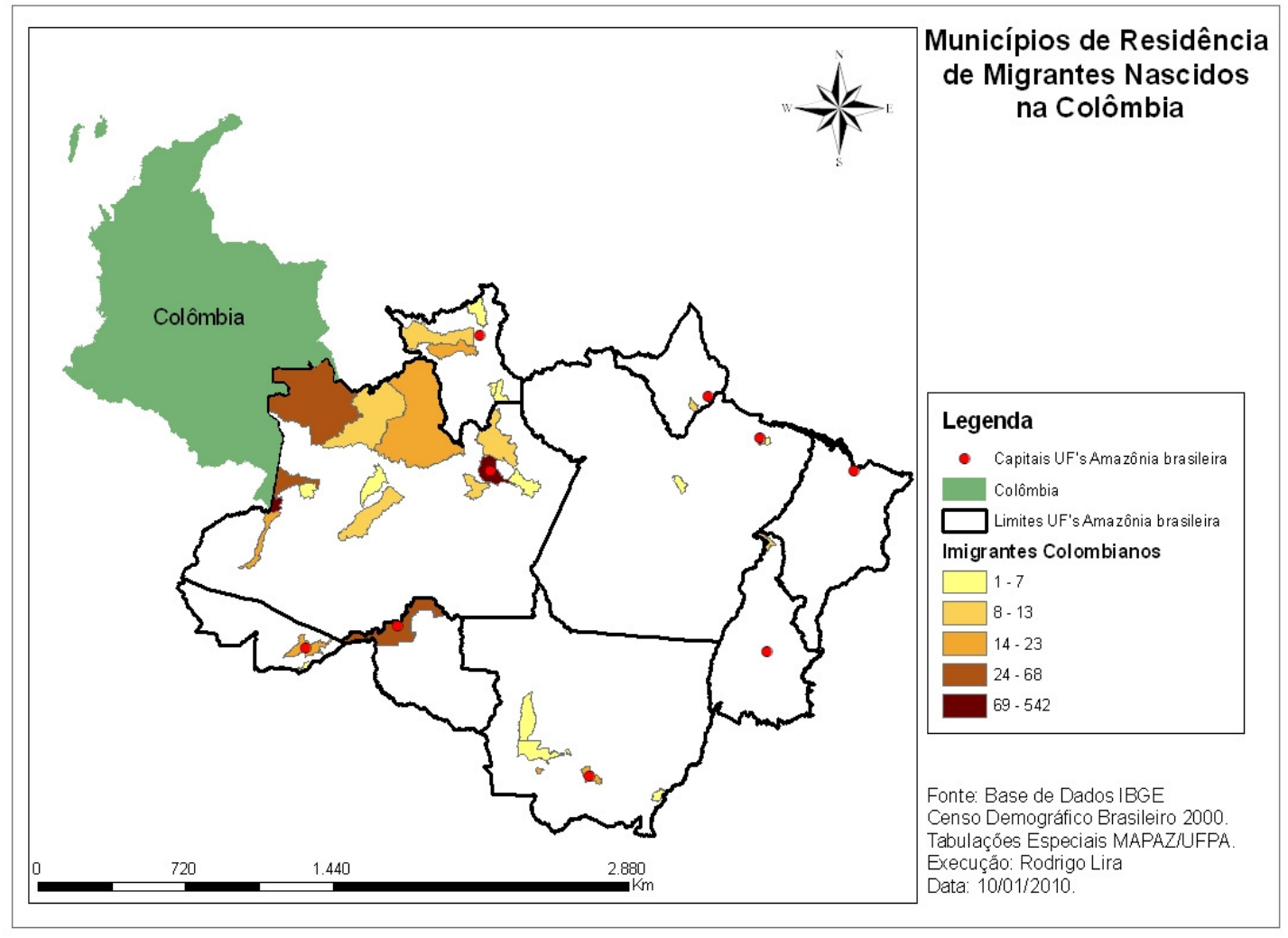

Fonte: IBGE, 2000. Elaborado por Lira (2010). 
Introdução ao Estudo da Migração Internacional na Amazônia

\section{Mapa 5}

Municípios de Residência, na Amazônia Brasileira, de Migrantes Nascidos na Venezuela

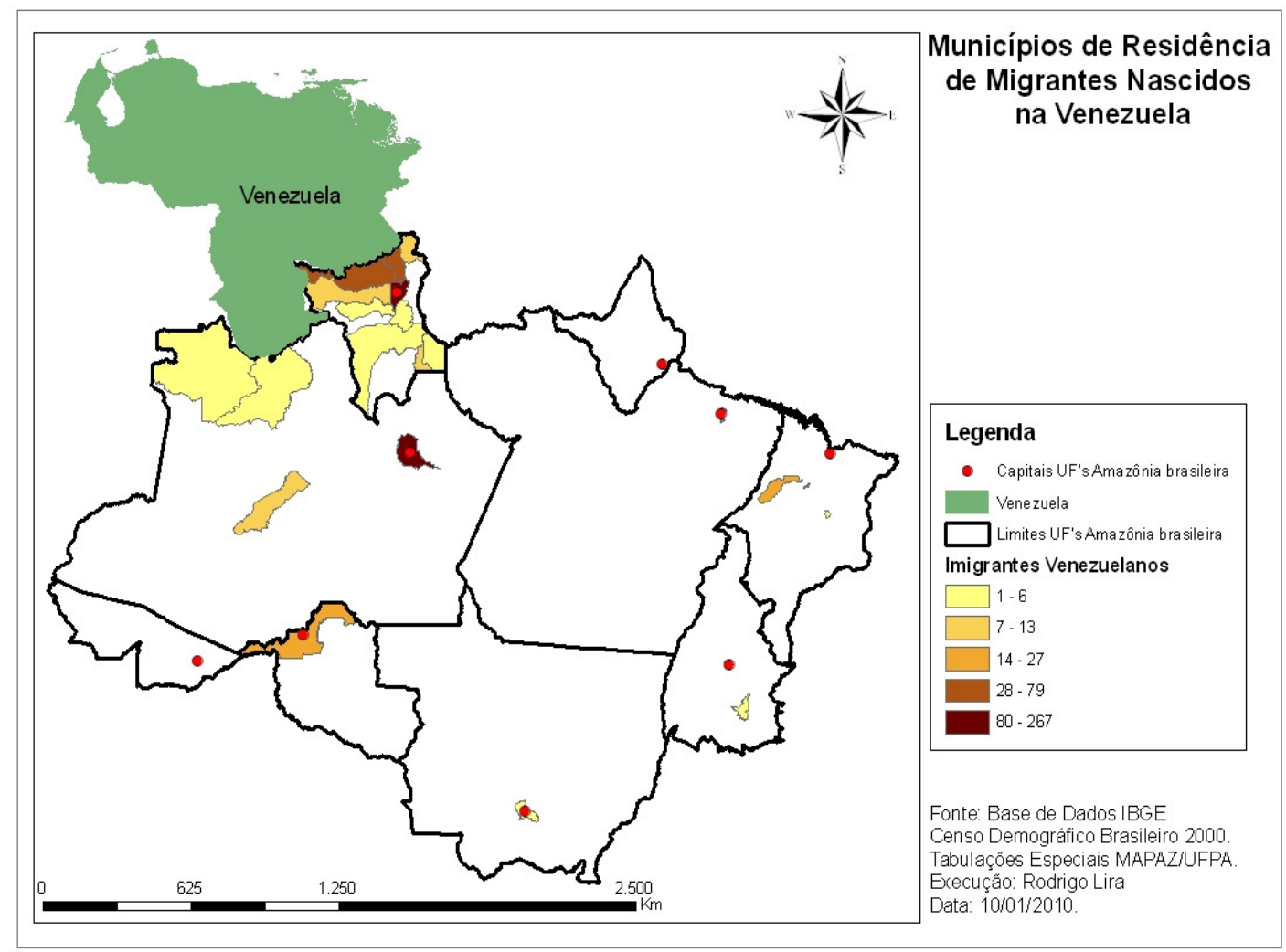

Fonte: IBGE, 2000. Elaborado por Lira (2010). 


\section{Luis E. Aragón}

\section{Mapa 6}

Municípios de Residência, na Amazônia Brasileira, de Migrantes Nascidos na Guiana

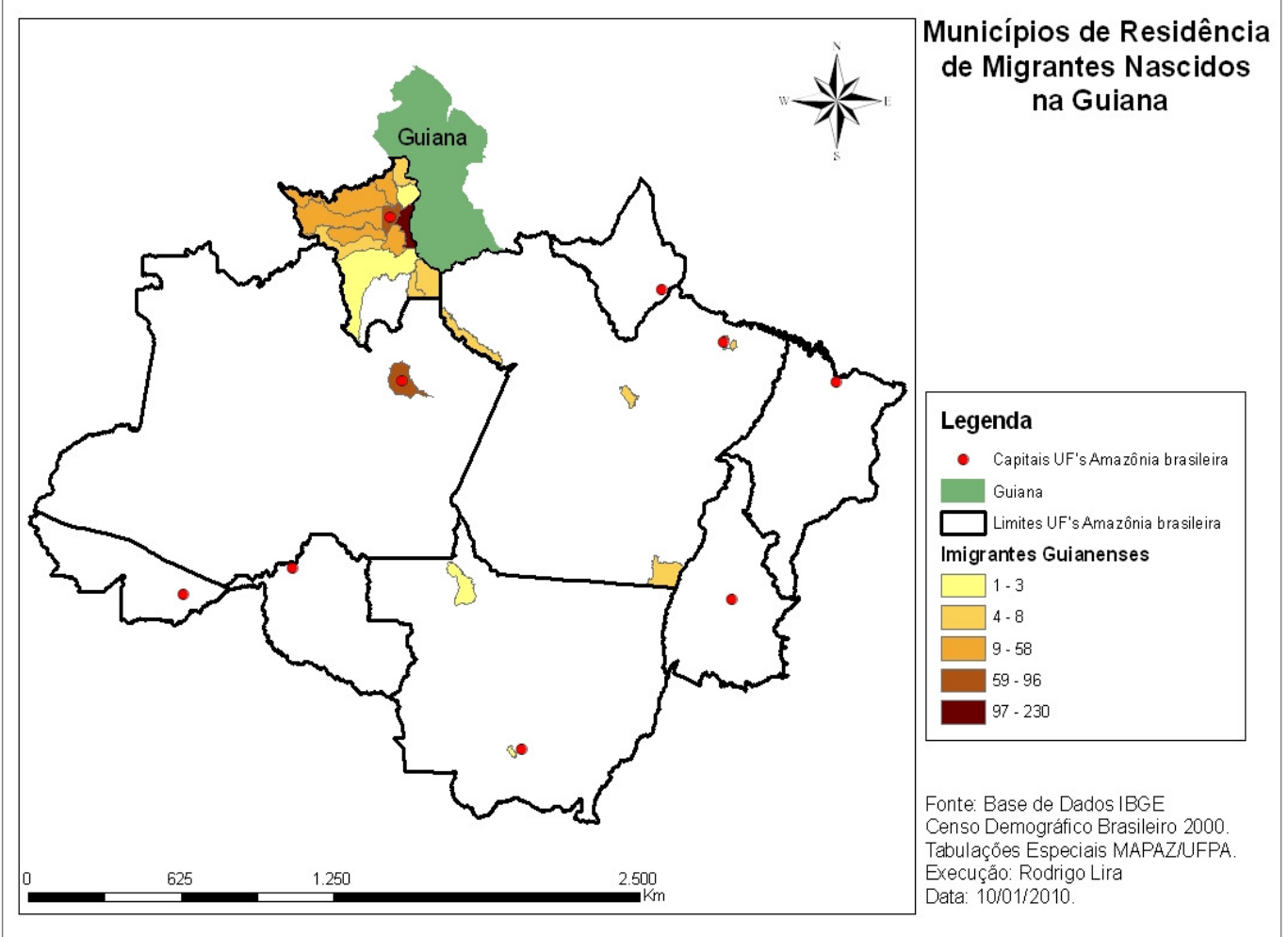

Fonte: IBGE, 2009. Elaborado por Lira (2010). 
Introdução ao Estudo da Migração Internacional na Amazônia

\section{Mapa 7}

Municípios de Residência, na Amazônia Brasileira, de Migrantes Nascidos no Suriname

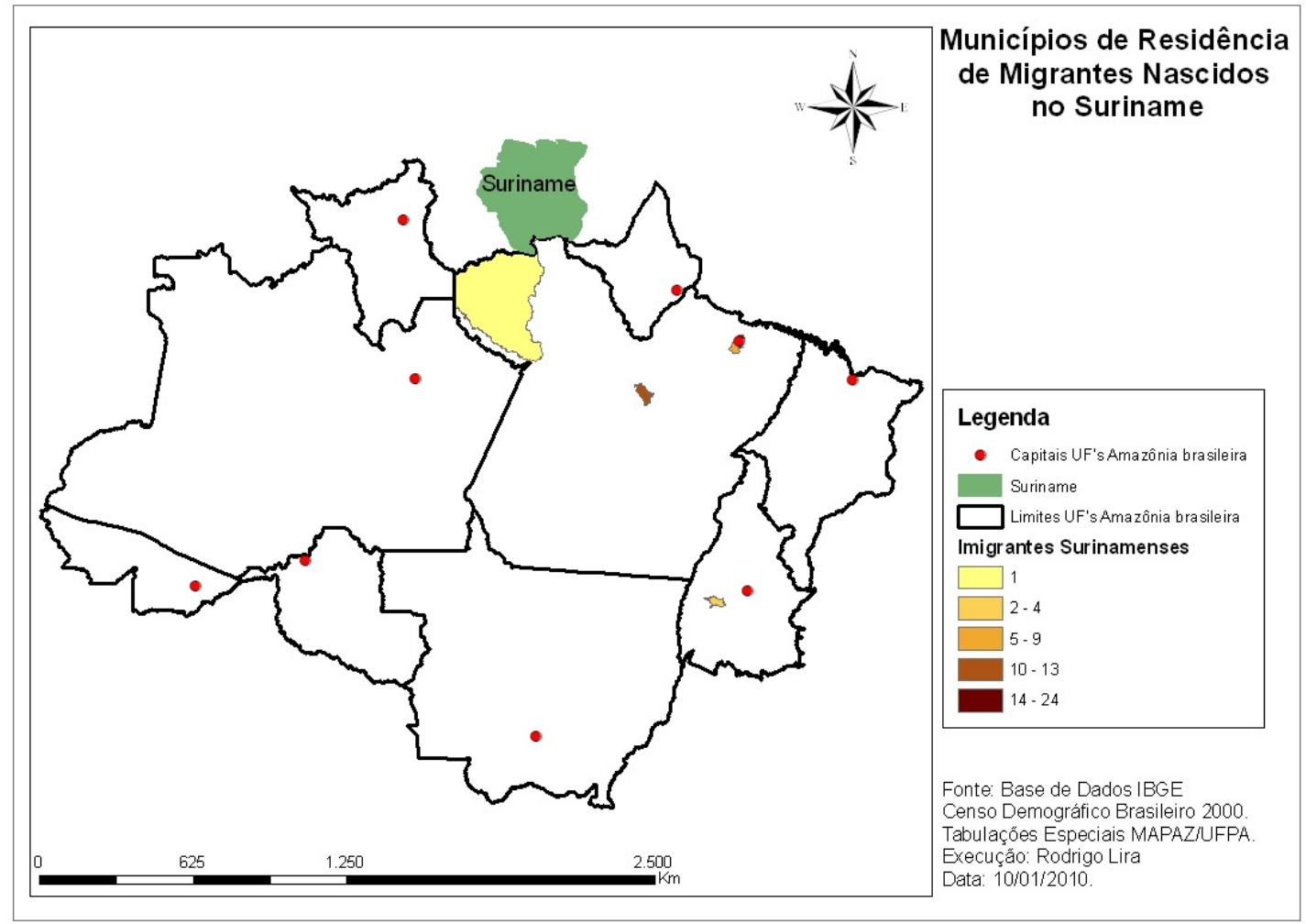

Fonte: IBGE, 2000. Elaborado por Lira (2010). 
Luis E. Aragón

\section{Mapa 8}

Municípios de Residência, na Amazônia Brasileira, de Migrantes Nascidos na Guiana Francesa

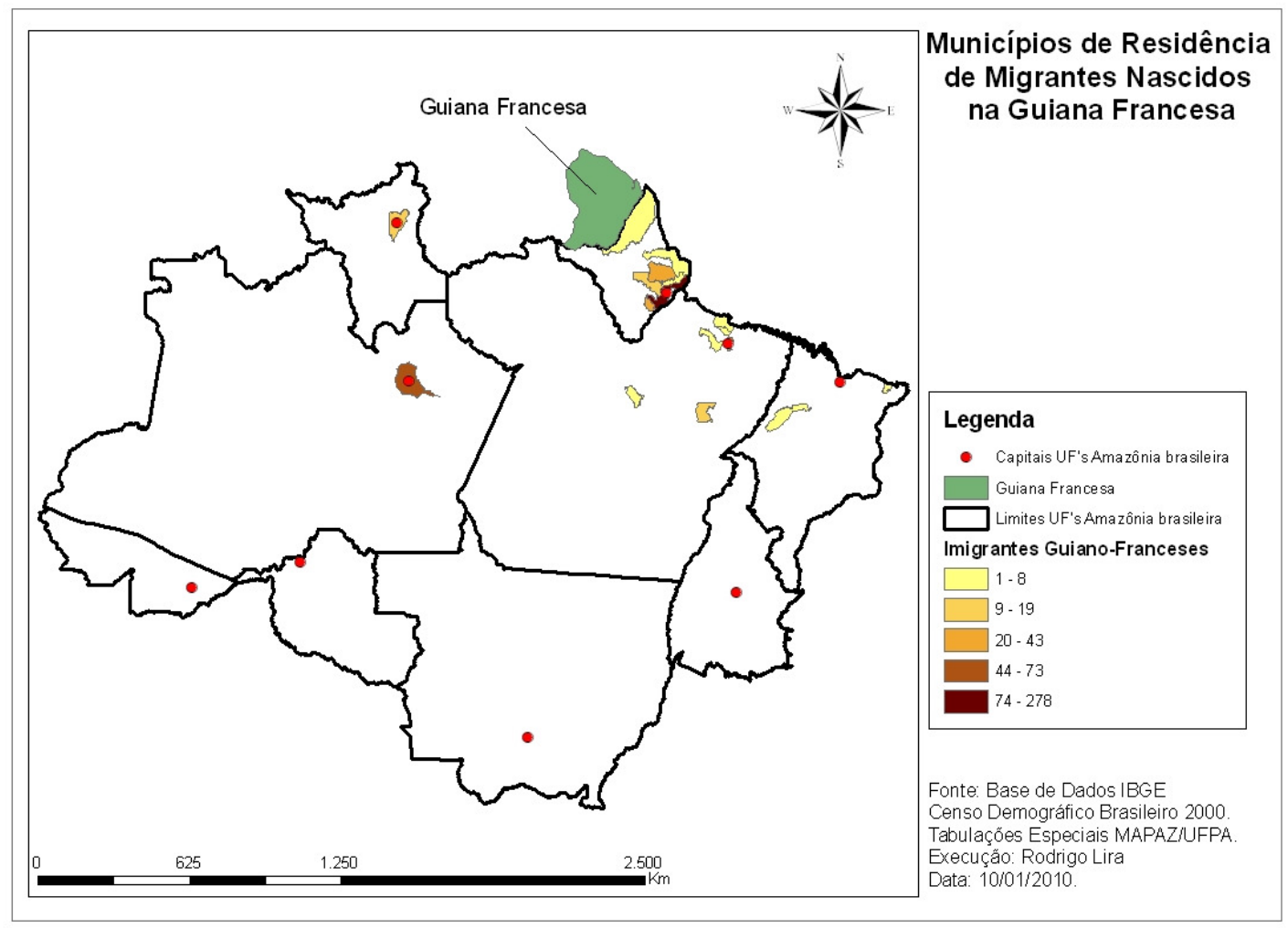

Fonte: IBGE, 2000. Elaborado por Lira (2010). 
Introdução ao Estudo da Migração Internacional na Amazônia

\section{Mapa 9}

Municípios de Residência, na Amazônia Brasileira, de Migrantes Nascidos no Equador

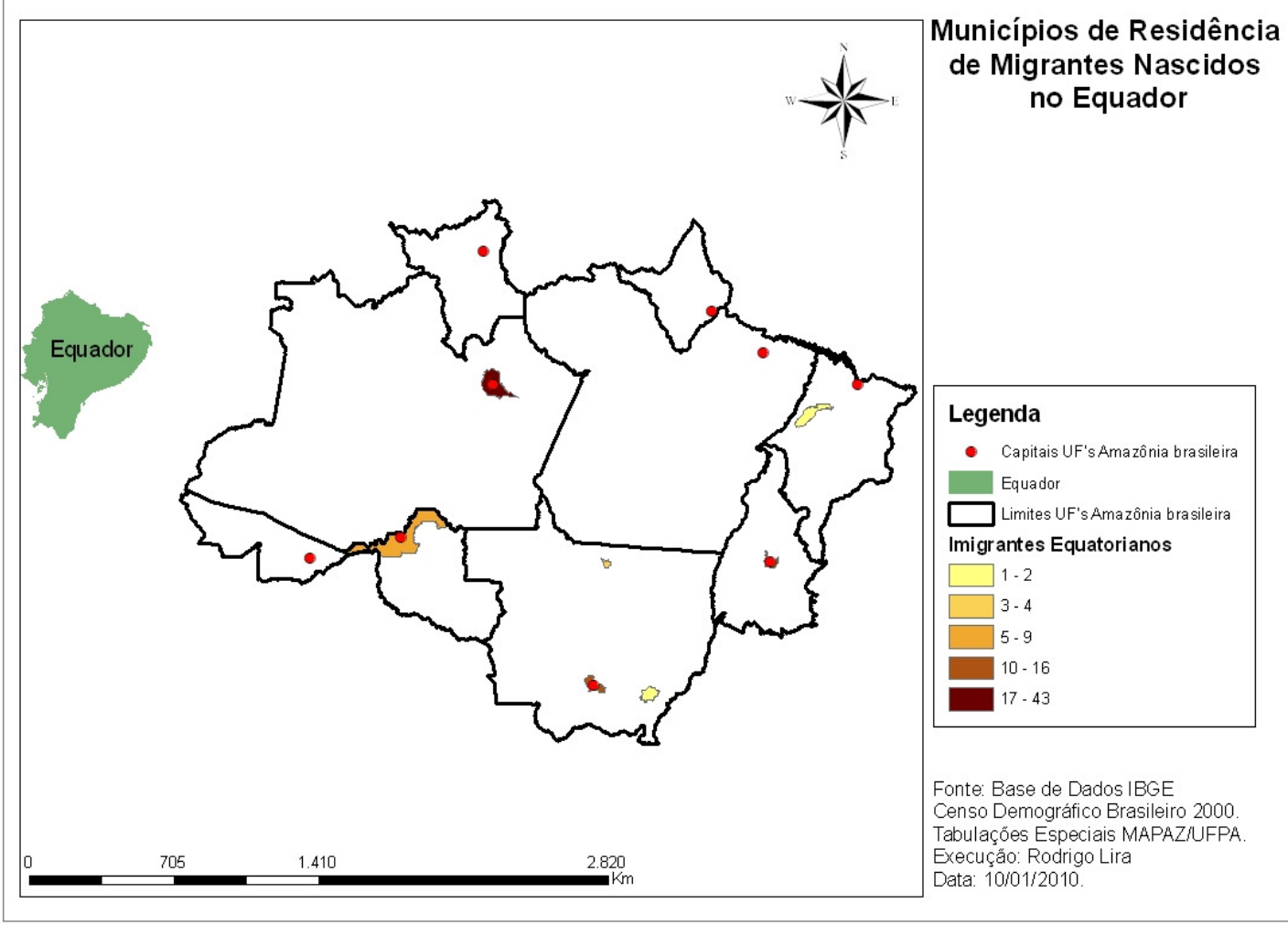

Fonte: IBGE, 2000. Elaborado por Lira (2010).

\section{Notas}

1 Esta e as demais citações de originais em língua estrangeira foram livremente traduzidas para este artigo.

2 Municípios no Brasil, na Bolívia, na Venezuela e na Colômbia; cantones no Equador e distritos no Peru.

3 Entre as limitações dos censos, podem-se enumerar as seguintes: 1) os baixos níveis de cobertura. No Brasil, por exemplo, há estimativas de que a imigração 
internacional ilegal ou clandestina na Amazônia possa ultrapassar muitas vezes aquela reportada pelo censo (SANTOS et. al., 2001). Ou seja, os números calculados pelos censos podem ser tomados, na realidade, somente como uma "amostra" da população total. 2) $\mathrm{O}$ ano dos censos difere consideravelmente, o que limita as comparações entre países. Os censos foram realizados em 2000 no Brasil; em 2001 no Equador, na Bolívia e na Venezuela; em 2002 na Guiana; em 2004 no Suriname; em 2005 na Colômbia; em 2006 na Guiana Francesa; e em 2007 no Peru. O Brasil realizou censo em 2010, mas os dados disponíveis não permitem ainda estudar a migração internacional. 3) Os quesitos referentes à migração internacional diferem entre os censos. Por exemplo, os censos do Peru, do Equador e da Colômbia incluem informação sobre emigrantes na base de respostas de membros de domicílio residindo no exterior no momento do censo, facilitando a quantificação dos fluxos, a caracterização das pessoas envolvidas, o cálculo das remessas enviadas e a comparação entre as características dos domicílios com ou sem membros no exterior, entre outros aspectos. Obviamente, a confiabilidade desse quesito depende da capacidade dos entrevistados em informar sobre os membros dos domicílios morando no exterior e da exclusão dos domicílios onde todos seus membros emigraram. 4) A acessibilidade da informação contida nos censos varia. Nos casos do Brasil, Bolívia, Peru, Equador, Colômbia e Venezuela, as informações mais detalhadas podem ser acessadas por meio do programa REDATAM. O censo da Guiana está parcialmente processado e uma síntese pode ser consultada pela internet. $\mathrm{O}$ censo do Suriname está disponível em forma impressa (em holandês, com alguns resumos em inglês), e o censo da Guiana Francesa está disponível no site do Instituto Nacional de Estatística e Estudos Econômicos da França (INSEE).

4 A Amazônia Legal brasileira integra os estados do Acre, Rondônia, Mato Grosso, Amazonas, Roraima, Amapá, Tocantins e Maranhão. No caso do Maranhão, mesmo que a definição da Amazônia Legal determine que só a parte oeste do Meridiano 44 integra a região, para facilitar a agregação de dados, esse estudo considerou todo o estado. Esse procedimento não altera os resultados da análise, conforme constatam Do Carmo e Jakob (2009). Os primeiros resultados do Censo de 2010 divulgados na página do IBGE reportam uma população total da Amazônia Legal (incluindo todo o Maranhão) de 25.469 .356 pessoas, o que representa 13,35\% da população total do país (190.732.694).

5 Desplazados são aquelas pessoas forçadas a deixar seus lares fugindo da violência produzida pelo conflito armado que se desenrola na Amazônia colombiana e em outras áreas do país. 


\section{Referências Bibliográficas}

AMARAL FILHO, Otacílio. A marca Amazônia: uma promessa publicitária para fidelização de consumidores globais. Tese (Doutorado em Desenvolvimento Sustentável do Trópico Úmido) - Universidade Federal do Pará, Belém, 2008.

ARAGÓN, Luis E. Até onde vai a Amazônia e qual é a sua população? In:

(Org.). Populações da Pan-Amazônia. Belém: NAEA, 2005a. p. 13-23.

(Org.). Populações da Pan-Amazônia. Belém: NAEA, $2005 b$.

. Novos temas regionais para o estudo da Amazônia no atual contexto internacional. In: FELDMAN, S.; FERNANDES, A. (Org.). O urbano e o regional no Brasil contemporâneo: mutações, tensões, desafios. Salvador: Universidade Federal da Bahia, 2007a. p. 153-174. $2007 \mathrm{~b}$.

(Org.). População e meio ambiente na Pan-Amazônia. Belém: NAEA,

(Org.). Migração internacional na Pan-Amazônia. Belém: NAEA, 2009a.

Aproximação ao estudo da migração internacional na Pan-Amazônia. In: (Org.). Migração internacional na Pan-Amazônia. Belém: NAEA, 2009b. p. 11-37.

; OLIVIERA, José Aldemir de (Org.). Amazônia no cenário SulAmericano. Manaus: EDUA, 2009.

AROUCK, Ronaldo. Brasileiros na Guiana Francesa: um grupo em integração? In: CASTRO, M. G. (Coord.). Migrações internacionais: contribuições para políticas. Brasília: Comissão Nacional de População e Desenvolvimento (CNPD), 2001. p. 327-343.

BAENINGER, Rosana. Brasileiros na América Latina: o que revela o Projeto IMILA-CELADE. In: CASTRO, M. G. (Coord.). Migrações internacionais: contribuições para políticas. Brasília: Comissão Nacional de População e Desenvolvimento (CNPD), 2001. p. 283-326.

BARRET, Ghislane. Guyane Française: historique de la population. In: ARAGÓN, L. E. (Org.). Populações da Pan-Amazônia. Belém: NAEA, 2005. p. 131140 . 
BELTRÃO, Kaizô Iwakami; CAMARANO, Ana Amélia. Cálculo de saldos e taxas líquidas de migração internacional. In: ABEP. Anais do Encontro Nacional sobre Migração. Curitiba: IPARDES/FNUP, 1998, p. 291-300.

BYNOE, Paulette; BRISTOL, Marlon. The human impact of capital flight in Guyana. In: ARAGÓN, Luis E. (Org.). Migração internacional na Pan-Amazônia. Belém: NAEA, 2009. p. 255-260.

CARVALHO, José Alberto Magno; CAMPOS, Marden Barbosa. A variação do saldo migratório internacional do Brasil. Estudos Avançados, v. 20, n. 57, p. 55$58,2006$.

CDEA - Commission on Development and Environment for Amazonia. Amazonia without myths. Washington, D.C.: IDB/UNDP/ACT, 1992.

CORBIN, Hisakhana. The social and environmental impacts of Brazilian migration to Guyana. In: ARAGÓN, Luis E. (Org.) População e meio ambiente na Pan-Amazônia. Belém: NAEA, 2007. p. 179-197.

. Migração internacional e desenvolvimento: o caso da Guiana. In: ARAGÓN, L. E. (Org.). Migração internacional na Pan-Amazônia. Belém: NAEA, 2009. p. 163-183.

DO CARMO, R. L; JAKOB, A. A. E. A migração estrangeira recente na Amazônia legal brasileira. In: ARAGÓN, L. E. (Org.). Migração Internacional na Pan-Amazônia. Belém: NAEA, 2009. p. 205-222.

FFLA - Fundación Futuro Latino Americano. Amazonia sostenible en el tercer milenio. Quito: FFLA, 2002.

GRASSERBAUER, Manfred. Prefácio. In: EVA, H. D.; HUBER, O. (Ed.). Proposta para definição dos limites geográficos da Amazônia. Luxemburgo: Comunidades Europeas, 2005. p. vii.

GUTIÉRREZ, Franz Rey; ACOSTA, Luis Eduardo Muñoz; SALAZAR, Carlos Ariel Cardona. Perfiles urbanos en la Amazonía: un enfoque para el desarrollo sostenible. Bogotá, D. C.: Instituto SINCHI, 2004.

HILY, Marie-Antoniette. As migrações contemporâneas: dos Estados e dos homens. In: Anais do Seminário Cultura e Tolerância. São Paulo, nov. 2003.

IMI - International Migration Institute. Para uma nova agenda de investigação sobre as migrações ineternacionais. University of Oxford, 2006. Disponível em: <http://www.imi.ox.ac.uk/pdfs/IMI>. Acesso em: 14 jan. 2011. 
INEI-OIM. Perú: características de los migrantes internacionales, hogares de origen y receptores de remesas. Lima: Organización Internacional para las Migraciones/Instituto Nacional de Estadística e Informática, 2007.

. Perú: estadísticas de la migración internacional de peruanos, 1990 2007. Lima: Organización Internacional para las Migraciones/Instituto Nacional de Estadística e Informática/Dirección General de Migraciones y Naturalización, 2008.

IOM - International Organization for Migration. Facts and figures - Global Estimates, 2010. Disponível em: <http://www.iom.int $>$. Acesso em: 14 jan. 2011.

JUBITHANA-FERNAND, Andrea. International migration in Suriname. In: ARAGÓN, L. E. (Org.). Migração internacional na Pan-Amazônia. Belém: NAEA, 2009. p. 185-204.

LEÓN, C.G.; MOGOLLÓN, F. P.; CAICEDO, G. A. Migración internacional en la Amazonía, Ecuador. In: ARAGÓN, L. E. (Org.). Migração Internacional na Pan-Amazônia. Belém: NAEA, 2009. p. 115-144.

LEVY, M. S. F. O papel da migração internacional na evolução da população brasileira (1872 a 1972). Revista Saúde Pública, n. 8 (supl.), p. 49-90, 1974,.

LIMACHI HUALLPA, Luis. Procesos migratorios en la Amazonía peruana: una mirada a las migraciones internacionales. In: ARAGÓN, L. E. (Org.). Migração internacional na Pan-Amazônia. Belém: NAEA, 2009. p. 97-113.

LIRA, J. R. O. Espacialização da migração internacional na Amazônia Brasileira. Trabalho de Conclusão de Curso (Licenciatura e Bacharelado em Geografia)-Universidade Federal do Pará, Belém, 2010.

MARTINE, George. A globalização inacabada: migrações internacionais e pobreza no século 21. São Paulo em Perspectiva, v. 19, n. 3, p. 3-22, 2005.

OLIVEIRA JR., Antonio de. Amazônia: a gênese de uma região de planejamento. In: ARAGÓN, L. E.; OLIVIERA, J. A. de (Org.). Amazônia no cenário SulAmericano. Manaus: EDUA, 2009. p. 41-77.

PATARRA, Neide Lopes; BAENINGER, Rosana. Mobilidade espacial da população no Mercosul, metrópoles e fronteira. Revista Brasileira de Ciências Sociais, v. 21 , n. 60 , p. 83-181, 2006. 
PELLEGRINO, Adela. La migración internacional en América Latina y el Caribe: tendencias y perfiles de los migrantes. Serie Población y Desarrollo (CEPAL), n. 35, 2003.

PINTO, M. J. S. Por uma "sociologia da clandestinidade" no estudo da presença de brasileiros na Guiana Francesa. In: ARAGÓN, L. E. (Org.). Migração Internacional na Pan-Amazônia. Belém: NAEA, 2009. p. 237-254.

PNUMA/OTCA - Programa das Nações Unidas para o Meio Ambiente/Organização do Tratado de Cooperação Amazônica. GEOAMAZÔNIA: perspectivas do meio ambiente na Amazônia. Brasília: PNUMA/OTCA, 2006.

RODRIGUES, F. S. Configuração migratória no lugar Guayana: uma análise da migração na tríplice fronteira Brasil-Venezuela-Guiana. In: ARAGÓN, L. E. (Org.). Migração Internacional na Pan-Amazônia. Belém: NAEA, 2009. p. 223-236.

SANDINO, O. Migración internacional en la Amazonía colombiana: aportes del censo de población 2005. In: ARAGÓN, L. E. (Org.). Migração Internacional na Pan-Amazônia. Belém: NAEA, 2009. p. 145-162.

SANTOS, Carlos Augusto dos; BRASIL, Marília Carvalho; MOURA, Hélio Augusto. "Personae non gratae?": A imigração indocumentada no estado do Amazonas. In: CASTRO, M. G. (Coord.). Migrações internacionais: contribuições para políticas. Brasília: Comissão Nacional de População e Desenvolvimento (CNDP), 2001. p. 479-488.

VARGAS BONILLA, M. A. V. Inmigración internacional de países amazónicos: el caso de Bolívia. In: ARAGÓN, L. E. (Org.). Migração Internacional na PanAmazônia. Belém: NAEA, 2009. p. 61-96.

YARZÁBAL, Luis; ESPINAL, Carlos; ARAGÓN, Luis E. (Org.). Enfoque integral de la salud humana en la Amazonia. Caracas: UNAMAZ, 1992. 


\section{Resumo}

\section{Introdução ao Estudo da Migração Internacional na Amazônia}

Apesar da importância que a migração internacional alcançou na mídia e na academia no mundo inteiro, existem somente uns poucos estudos esparsos sobre a migração internacional na Amazônia. Como se apresenta o processo de migração internacional na Amazônia e qual é a sua importância nos destinos da região? Este artigo busca se aproximar da resposta a essa pergunta. O texto sintetiza resultados de investigações recentes realizadas pelo Grupo de Pesquisa Meio Ambiente, População e Desenvolvimento da Amazônia (MAPAZ), do Núcleo de Altos Estudos Amazônicos (NAEA) da Universidade Federal do Pará. Primeiramente, destaca-se a dificuldade de se definir a Amazônia; posteriormente, são apresentadas algumas considerações sobre a migração internacional em nível da Grande Região, agregando os migrantes acumulados nas respectivas Amazônias nacionais, conforme os censos de população de cada país; e, finalmente, trata-se essa problemática no caso da Amazônia brasileira, destacando os países de nascimento e a distribuição espacial dos migrantes na Amazônia Legal. Na Amazônia, os padrões e as tendências discutidas aqui se tornarão mais dinâmicos e complexos em função do andamento de políticas de desenvolvimento na busca da integração regional e econômica.

Palauras-chave: Migração Internacional - Grande Amazônia - Países Amazônicos - Amazônia Brasileira

\section{Abstract}

\section{Introduction to the Study of International Migration in the Amazon}

Despite the importance that international migration has attained in the media and academia worldwide, there are only a few scattered studies on international migration in the Amazon. How is the process of international migration presented in the Amazon and what is its importance in the destiny of the region? This 
article is an initial approach to that question. The text summarizes results of recent research conducted by the Research Group on Environment, Population and Development in the Amazon (MAPAZ) of the Center for Advanced Amazonian Studies (NAEA) of the Federal University of Pará. First, it discusses the difficulty of defining the Amazon, then some considerations are made about international migration in the Greater Amazon Region, aggregating the accumulated migrants of the national portions, according to the census of population of each country, and, finally, this issue is considered with regard to Brazilian Amazon highlighting countries of birth and the spatial distribution of migrants in the Amazon. In the Amazon the patterns and trends discussed here will become more dynamic and complex as development policies in pursuit of regional integration and economic development advance.

Keywords: International Migration - The Greater Amazon - Amazonian Countries - Brazilian Amazon 